\title{
Relation between Hertz Stress-Life Exponent, Ball-Race Conformity, and Ball Bearing Life
}

\author{
Erwin V. Zaretsky, Fellow STLE \\ National Aeronautics and Space Administration \\ Glenn Research Center \\ Cleveland, Ohio 44135 \\ Joseph V. Poplawski, Member STLE \\ J.V. Poplawski \& Associates \\ Bethlehem, Pennsylvania 18018 \\ Lawrence E. Root, Member STLE \\ Lawrence E. Root, P.E. \\ Lebanon, New Hampshire 03766
}

\begin{abstract}
ANSI/ABMA and ISO standards based on Lundberg-Palmgren bearing life theory are normalized for ball bearings having inner- and outer-race conformities of 52 percent (0.52) and made from pre-1940 bearing steel. The Lundberg-Palmgren theory incorporates an inverse 9th power relation between Hertz stress and fatigue life for ball bearings. The effect of race conformity on ball set life independent of race life is not incorporated into the Lundberg-Palmgren theory. In addition, post-1960 vacuum-processed bearing steel exhibits a 12th power relation between Hertz stress and life. The work reported extends the previous work of Zaretsky, Poplawski, and Root to calculate changes in bearing life - that includes the life of the ball set—caused by race conformity, Hertz stresslife exponent, ball bearing type and bearing series. The bearing fatigue life in actual application will usually be equal to or greater than that calculated using the ANSI/ABMA and ISO standards that incorporate the LundbergPalmgren theory. The relative fatigue life of an individual race is more sensitive to changes in race conformity for Hertz stress-life exponent $\boldsymbol{n}$ of 12 than where $\boldsymbol{n}=9$. However, when the effects are combined to predict actual bearing life for a specified set of conditions and bearing geometry, the predicted life of the bearing will be greater for a value of $\boldsymbol{n}=12$ than $\boldsymbol{n}=9$.
\end{abstract}


Keywords: Rolling-element bearings, Bearing life, Race conformity, Bearing geometry, Stress-life exponent

\section{Nomenclature}

a semimajor axis of the Hertzian contact ellipse, half the width of the race contact

$a_{1}$ ANSI/ABMA/ISO life factor for reliability

$\boldsymbol{a}_{2}$ ANSI/ABMA/ISO life factor for special bearing properties

$\boldsymbol{a}_{3} \quad$ ANSI/ABMA/ISO life factor for operating conditions

b semiminor axis of the Hertzian contact ellipse

$\boldsymbol{C}_{\boldsymbol{D}} \quad$ dynamic load capacity, N (lbf)

$\boldsymbol{D}_{\boldsymbol{i}} \quad$ diameter of ball-race contacts of inner race, m (in.)

Do diameter of ball-race contacts of outer race, m (in.)

d ball diameter, $\mathrm{m}$ (in.)

$\boldsymbol{d}_{\boldsymbol{e}} \quad$ pitch diameter, $\mathrm{m}$ (in.)

$\boldsymbol{e} \quad$ Weibull slope

f conformity, percent or decimal

$\boldsymbol{f}_{c}, \boldsymbol{f}_{c \boldsymbol{m}}$ bearing geometry and material coefficient

$\boldsymbol{h}$ exponent

$\boldsymbol{i} \quad$ number of rows of balls

$\boldsymbol{K} \quad$ geometry-load constant

$\boldsymbol{k} \quad$ correction factor for stressed volume

$\boldsymbol{L} \quad$ life, number of stress cycles inner-race rev. or $\mathrm{hr}$

$\boldsymbol{L}_{\mathbf{1 0}}$ 10-percent life, or life at which 10 percent of a population fails, number of stress cycles or hr

$\boldsymbol{L F} \quad$ life factor

$\boldsymbol{l} \quad$ race track length, $\mathrm{m}$ (in.)

$\boldsymbol{N} \quad$ number of stress cycles per inner-race revolution

n Hertz stress-life exponent

$\boldsymbol{P}_{\boldsymbol{D}}$ diametral internal clearance, $\mathrm{m}$ (in.)

$\boldsymbol{P}_{\text {eq }} \quad$ equivalent radial load, N (lbf) 


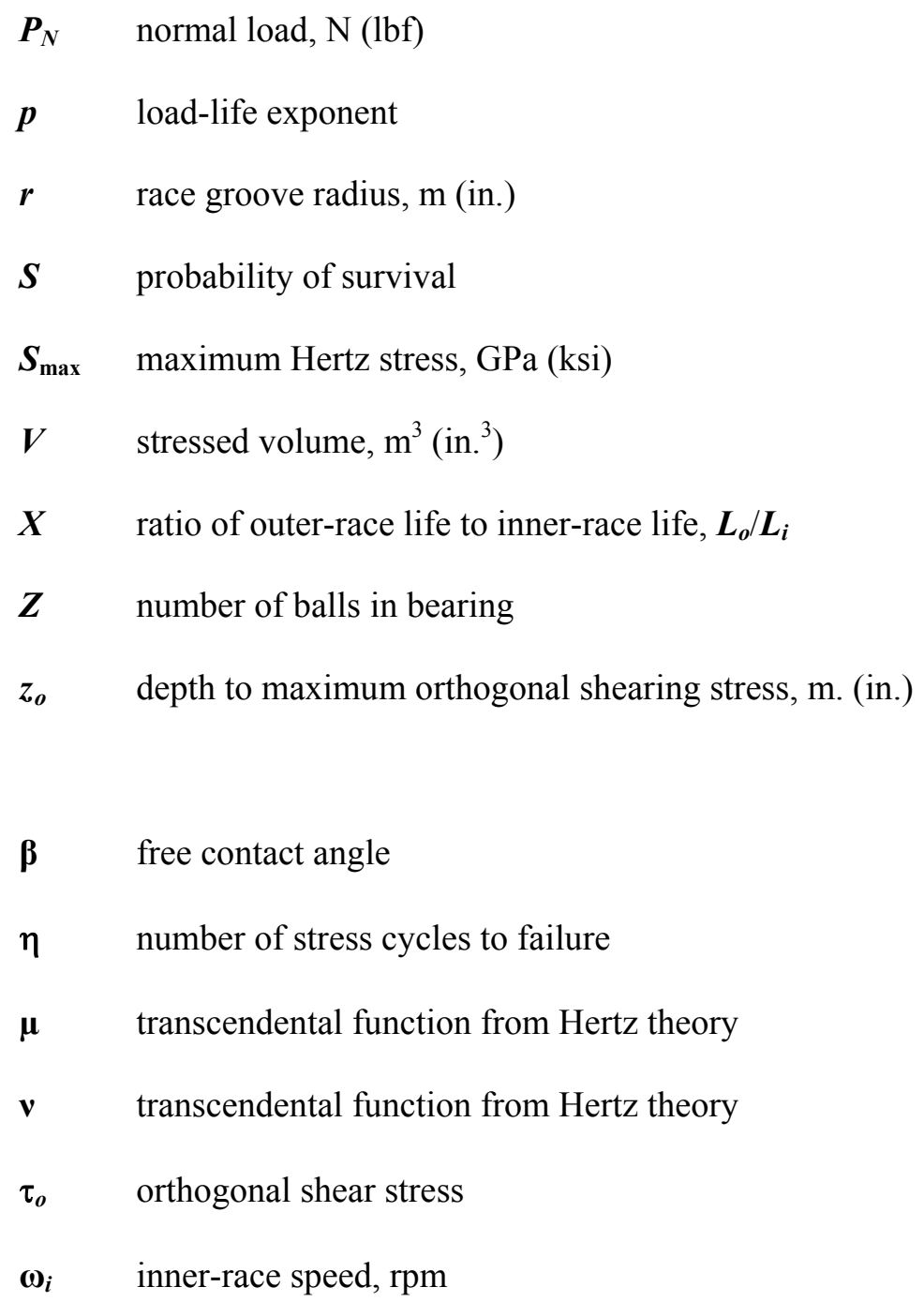

\section{Subscripts}

c race conformity

$\boldsymbol{i} \quad$ inner race

$\boldsymbol{m} \quad$ modified based on race conformity

o outer race

re rolling element (ball)

$\mathbf{0 . 5 2} 52$ percent race conformity

\section{Definitions}

ABMA American Bearing Manufactures Association

ANSI American National Standards Institute 
IDC internal diametrical clearance

ISO International Organization for Standardization

\section{Introduction}

In 1947, G. Lundberg and A. Palmgren [1] established the primary relation between bearing geometry and bearing life. For ball bearings they related bearing life to 5 variables. These are ball diameter, pitch diameter, inner- and outer-race conformities, number of balls and contact angle. Except for bearing contact angle, the relation between these parameters remains the same regardless of whether the bearing is a deep-groove ball bearing or an angular-contact ball bearing. These relations have been incorporated into both the ANSI/ABMA and the ISO standards to predict bearing fatigue life as well as current life prediction bearing codes [2-6]. The Lundberg-Palmgren theory [1] only relates to the lives of the inner and outer races and incorporates ball-set life into their analysis by inference. It has since been recognized that the life of the ball set in relation to the races is different for a deep-groove ball bearing and an angular-contact ball bearing as well as being dependent on the relative contact (Hertz) stresses at the inner and outer races [7].

While Lundberg and Palmgren allow for calculating the effect of ball bearing race conformities into their life calculation, the standards and the bearing manufacturers' catalogs generally normalize their ball bearing lives to conformities on the inner and outer races of 52 percent (0.52). ANSI/ABMA Standard 12.1 and $12.2[5,6]$ for instrument bearings contain other representative combinations of inner- and outer-race conformities. However, the standard does not distinguish between deep-groove (radially-loaded) and angular-contact (thrust-loaded) ball bearings nor does it separate the effect of ball life from that of the raceway.

Analysis reported by Zaretsky, Poplawski, and Root [8] determined the effect of ball-race conformity on ball bearing life and considers the life of the ball set independent of the lives of the races. The related changes in ball bearing life are incorporated in life factors that can be used to modify the bearing predicted life using the Lundberg-Palmgren theory and the ANSI/ABMA and the ISO standards. 
Two simple algebraic relationships were established by Zaretsky, Poplawski, and Root [8] that calculate life factors $\left(\mathbf{L F}_{\mathbf{c}}\right)$ that determine how the inner- and outer-race conformity combinations that include associative ball set life affect bearing $\boldsymbol{L}_{\mathbf{1 0}}$ life (the time at which 10 percent of the population fails), for deep-groove and angularcontact ball bearings, respectively. Depending on the bearing type and series as well as conformity combinations, the calculated life for deep-groove ball bearings can be over 40 percent less than that calculated by the LundbergPalmgren equations. For angular-contact ball bearings, the life can vary from 16 percent to -39 percent difference from that calculated by the Lundberg-Palmgren equations. Comparing the two ball bearing types, the life factors $\boldsymbol{L F}_{c}$ for the deep-groove bearings can be as much as 34 percent lower than that for angular-contact ball bearings.

The Lundberg-Palmgren theory [1] incorporates an inverse 9th power relation between Hertz stress and fatigue life for ball bearings. Except for differences in applied loading, both deep-groove and angular-contact ball bearings are treated identically. Post-1960 vacuum-processed bearing steels exhibit a 12th power relation between Hertz stress and life [9]. The objective of the work reported is to extend previous work of Zaretsky, Poplawski, and Root [8] to include the 12th power relation between ball bearing fatigue life and maximum Hertz stress.

\section{Ball Bearing Geometry and Stress}

\section{Bearing Geometry}

Figure 1(a) is a schematic of a deep-groove ball bearing. While there are several types of ball bearings, there are two common basic types: the deep-groove ball bearing (Figs. 1 and 2(a)) that is designed to handle primarily radial loads and the angular-contact ball bearing (Fig. 2(b)) designed to handle primarily thrust loads. These bearings comprise several balls interspersed between an inner- and outer race and normally separated and positioned by a cage or separator.

Where the internal diametral clearance $\boldsymbol{P}_{\boldsymbol{D}}=0$, the bearing pitch diameter is

$$
d_{e}=\frac{\left(D_{o}+D_{i}\right)}{2}
$$


Referring to Fig. 2, race curvature (race groove radius) $r$ is "a measure of the conformity of the race to the ball in a plane passing through the bearing axis and transverse to the raceway diameter and expressed as a percent or decimal" [10]. Where $f$ is the conformity,

$$
f=\frac{r}{d}
$$

The race curvature can then be expressed as

$$
r=f d
$$

\section{Contact (Hertz) Stress}

The contact (Hertz) stresses at the respective races of a bearing are a function of the bearing geometry, the normal load at the contact, and the elastic properties of the bearing materials. Jones [10] relates the Hertz contact theory for the stresses of nonconforming bodies in contact for both ball and roller bearings. From Jones [10], the following relations for the maximum Hertz stresses $\boldsymbol{S}_{\max }$ at the inner and outer races of ball bearings can be derived.

I. For deep-groove ball bearings with a radial load only where $\boldsymbol{P}_{\boldsymbol{N}_{\max }}$ is the maximum normal load on a ball, the maximum Hertz stresses at the inner and outer races are as follows:

$$
\boldsymbol{S}_{\max _{o}}=\frac{K\left(-\frac{2}{D_{o}}+\frac{4}{d}-\frac{1}{f_{o} d}\right)^{2 / 3} P_{N_{\max }}^{1 / 3}}{(\mu \nu)_{o}}
$$

for the outer race and 


$$
\boldsymbol{S}_{\max _{i}}=\frac{\boldsymbol{K}\left(\frac{2}{\boldsymbol{D}_{i}}+\frac{4}{\boldsymbol{d}}-\frac{1}{\boldsymbol{f}_{i} \boldsymbol{d}}\right)^{2 / 3} \boldsymbol{P}_{N_{\max }}^{1 / 3}}{(\mu \nu)_{i}}
$$

for the inner race.

II. For angular-contact ball bearings with a thrust load only, the maximum Hertz stresses at the inner and outer races are as follows:

$$
\boldsymbol{S}_{\max _{o}}=\frac{\boldsymbol{K}\left(-\frac{2 \cos \beta}{\boldsymbol{d}_{\boldsymbol{e}}+\boldsymbol{d} \cos \beta}+\frac{4}{\boldsymbol{d}}-\frac{1}{\boldsymbol{f}_{\boldsymbol{o}} \boldsymbol{d}}\right)^{2 / 3} \boldsymbol{P}_{N}^{1 / 3}}{(\mu \nu)_{\boldsymbol{o}}}
$$

for the outer race and

$$
\boldsymbol{S}_{\max _{i}}=\frac{\boldsymbol{K}\left(\frac{2 \cos \beta}{\boldsymbol{d}_{\boldsymbol{e}}-\boldsymbol{d} \cos \beta}+\frac{4}{\boldsymbol{d}}-\frac{1}{\boldsymbol{f}_{i} \boldsymbol{d}}\right)^{2 / 3} \boldsymbol{P}_{N}^{1 / 3}}{(\mu v)_{i}}
$$

for the inner race.

For bearing steel against bearing steel and values of $\boldsymbol{S}_{\max }$ in GPa, $\boldsymbol{K}=1.58 \times 10^{-3}$, and for values in ksi, $\boldsymbol{K}=$ 23.58. The values of the transcendental functions, $\mu$ and $\nu$ vary with conformity $f$ and can be found in Ref. [10].

\section{Bearing Life Analysis}

\section{Bearing Fatigue Life Prediction}

In 1939, Weibull [11-13] developed a method and an equation for statistically evaluating the fracture strength of materials based upon small sample (population) sizes. This method can be and has been applied to analyze, determine, and predict the cumulative statistical distribution of fatigue failure or any other phenomenon or physical characteristic that manifests a statistical distribution. 
Based on the work of Weibull [11], Lundberg and Palmgren [1] in 1947 showed that the probability of survival $S$ could be expressed as a power function of the orthogonal shear stress $\tau_{\boldsymbol{o}}$, life $\eta$, depth to the maximum orthogonal shear stress $z_{o}$, and stressed volume $\boldsymbol{V}$. That is,

$$
\ln \frac{1}{S} \sim \tau_{o} \frac{\eta^{e}}{z_{o}^{h}} V
$$

for

$$
\boldsymbol{V}=\boldsymbol{a z _ { o }} \boldsymbol{l}
$$

where $\boldsymbol{a}$ and $\boldsymbol{z}_{\boldsymbol{o}}$ are functions of the maximum Hertz stress $\boldsymbol{S}_{\max }$ and $\boldsymbol{l}$ is the length of the running track of the rolling elements, usually the circumference of the inner or outer raceway of a bearing (Fig. 3).

The Lundberg-Palmgren theory for bearing life prediction was discussed in detail in a previous paper [14]. In order to predict bearing life, Lundberg and Palmgren [1] formulated from Eq. (5) the following relation for rolling-element bearings:

$$
L_{10}=\left(\frac{C_{D}}{P_{\mathrm{eq}}}\right)^{p}
$$

From Lundberg-Palmgren [1], the load-life exponent $\boldsymbol{p}=3$ for ball bearings.

Equation (6) can be modified using life factors based on reliability $\boldsymbol{a}_{\mathbf{1}}$, materials and processing $\boldsymbol{a}_{2}$, and operating conditions such as lubrication $\boldsymbol{a}_{3}[7]$ such that

$$
L=a_{1} a_{2} a_{3} L_{10}
$$


Formulas for the basic load capacity for ball bearings derived from Lundberg and Palmgren [1] and incorporated into the ANSI/ABMA standards $[3,4]$ and the ISO standards [2] are as follows:

For ball bearings with ball diameter $\boldsymbol{d} \leq 25 \mathrm{~mm}$ and contact angle $\boldsymbol{\beta} \leq 45^{\circ}$,

$$
C_{D}=\boldsymbol{f}_{c m}(\boldsymbol{i} \cos \beta)^{0.7} \boldsymbol{Z}^{2 / 3} \boldsymbol{d}^{1.8}
$$

and for ball bearings with $\boldsymbol{d}>25 \mathrm{~mm}$ and $\boldsymbol{\beta} \leq 45^{\circ}$,

$$
C_{D}=\boldsymbol{f}_{\boldsymbol{c m}}(\boldsymbol{i} \cos \boldsymbol{\beta})^{0.7} \boldsymbol{Z}^{2 / 3} \boldsymbol{d}^{1.4}
$$

where $\boldsymbol{f}_{\boldsymbol{c} m}$ is the bearing geometry and material coefficient. Prior to 1990 , the coefficient $\boldsymbol{f}_{\boldsymbol{c} m}$ was designated as $\boldsymbol{f}_{\boldsymbol{c}}$ [7]. The bearing geometry including race conformities are incorporated into this coefficient. The ball bearing standards normalize the values of $\boldsymbol{f}_{c m}$ to inner- and outer-race conformities of 52 percent $(0.52)$.

The above relations are based on a relationship between ball bearing fatigue life maximum Hertz stress, $\boldsymbol{S}_{\max }$, and equivalent bearing load, $\boldsymbol{P}_{\text {eq }}$, where

$$
\boldsymbol{L} \sim\left(\frac{1}{\boldsymbol{P}_{\mathrm{eq}}}\right)^{p} \sim\left(\frac{1}{\boldsymbol{S}_{\mathrm{max}}}\right)^{n}
$$

From Hertz theory [10],

$$
p=\frac{n}{3}
$$


As previously discussed, the Lundberg-Palmgren theory for ball bearings incorporates a value of the load-life exponent $\boldsymbol{p}=3$ arising from a Hertz stress-life exponent, $\boldsymbol{n}=9$. These values are based on pre-1940, air-melt, AISI 52100 steel. Based on the data reported by Parker and Zaretsky [9] and summarized in Ref. [7] for vacuumprocessed post-1960 bearing steels, the value of the load-life exponent $\boldsymbol{p}$ for ball bearings is 4 arising from a Hertz-stress-life exponent, $\boldsymbol{n}=12$. Accordingly, the standards underpredict ball bearing life by a factor of $\left(\boldsymbol{C}_{\boldsymbol{D}} / \boldsymbol{P}_{\boldsymbol{e q}}\right)$.

\section{Life Ratio of Outer to Inner Race}

From Eqs. (5a) and (5b), the fatigue life $\boldsymbol{L}$ of a bearing inner or outer race determined from the LundbergPalmgren theory [1] can be expressed as follows:

$$
\boldsymbol{L} \sim\left(\frac{1}{S_{\max }}\right)^{n}\left(\frac{1}{l}\right)^{1 / e}\left(\frac{1}{N}\right)
$$

where $N$ is the number of stress cycles.

The ratio of outer- to inner-race life is

$$
\frac{L_{o}}{L_{i}}=\left(\frac{S_{\max _{i}}}{S_{\max _{o}}}\right)^{n}\left(\frac{\boldsymbol{l}_{i}}{\boldsymbol{l}_{\boldsymbol{o}}}\right)^{1 / e}\left(\frac{N_{i}}{N_{o}}\right)
$$

In general, for angular-contact and deep-groove ball bearings,

$$
l_{i}=\pi D_{i}=\pi\left(d_{e}-d \cos \beta\right)
$$

and

$$
l_{o}=\pi D_{o}=\pi k\left(d_{e}+d \cos \beta\right)
$$


In Eq. (13b), $\boldsymbol{k}$ is a correction factor that can account for variation of the stressed volume in the outer raceway. Equations (13a) and (13b) without the correction factor $\boldsymbol{k}$ are used in the Lundberg-Palmgren theory [1] to develop the capacity of a single contact on a raceway, assuming that all the ball-raceway loads are the same. In Eq. (13b), for an angular-contact bearing under thrust load only, $\boldsymbol{k}=1$.

Under radial load and no misalignment, the stressed volume $\boldsymbol{V}$ of a stationary outer race in a deep-groove ball bearing varies along the outer raceway in a load zone equal to or less than $180^{\circ}$. In the ANSI/ABMA and ISO standards [2, 3] for radially loaded, deep-groove ball bearings, Eqs. (13a) and (13b) are adjusted for inner-race rotation and a fixed outer race with zero internal clearance, using system-life equations for multiple single contacts to calculate the bearing fatigue life. The outer raceway has a maximum load zone of $180^{\circ}$. An equivalent radial load $\boldsymbol{P}_{\text {eq }}$ was developed by Lundberg and Palmgren [1] and used in the standards [2, 3]. The equivalent load $\boldsymbol{P}_{\text {eq }}$ mimics a $180^{\circ}$ ball-race load distribution assumed in the standards when pure axial loads are applied. It is also used throughout the referenced standards when combined axial and radial loads are applied in an angular-contact ball bearing.

Equations (13a) and (13b) are applicable for radially loaded deep-groove ball bearings where the ball-raceway contact diameters are at the pitch diameter plus or minus the ball diameter, $\cos \boldsymbol{\beta}=1$, and $\boldsymbol{k}<1$. The maximum Hertz stress values are different at each ball-race contact, at the inner and outer races, and vary along the arc in the zone of contact in a predictable manner. The width of the contact $2 \boldsymbol{a}$ and the depth $\boldsymbol{z}_{\boldsymbol{o}}$ to the critical shearing stress $\tau_{\boldsymbol{o}}$ are functions of the maximum Hertz stress and are different at the inner and outer race contacts.

From Jones [10], for a ball bearing with a rotating inner race and a stationary outer race, the stress cycles $\boldsymbol{N}_{i}$ and $\boldsymbol{N}_{\boldsymbol{o}}$ as a function of inner-race speed $\boldsymbol{r}_{i}$ for single points on the inner- and outer-races, respectively, are

$$
N_{i}=\frac{Z}{2}\left(\frac{r_{i}}{60}\right)\left(1+\frac{d}{d_{e}} \cos \beta\right)
$$




$$
\begin{gathered}
N_{o}=\frac{Z}{2}\left(\frac{r_{i}}{60}\right)\left(1-\frac{d}{d_{e}} \cos \beta\right) \\
\frac{N_{i}}{N_{o}}=\frac{\left(1+\frac{d}{d_{e}} \cos \beta\right)}{\left(1-\frac{d}{d_{e}} \cos \beta\right)}
\end{gathered}
$$

Next, substitute Eqs. (13a), (13b), and (14c) into Eq. (12) and let

$$
X=\frac{L_{o}}{L_{i}}
$$

For angular-contact and deep-groove ball bearings,

$$
\begin{aligned}
\boldsymbol{X}=\frac{\boldsymbol{L}_{\boldsymbol{o}}}{\boldsymbol{L}_{\boldsymbol{i}}} & =\left(\frac{\boldsymbol{S}_{\max _{i}}}{\boldsymbol{S}_{\max _{o}}}\right)^{n}\left(\frac{\boldsymbol{d}_{\boldsymbol{e}}-\boldsymbol{d} \cos \boldsymbol{\beta}}{\boldsymbol{d}_{\boldsymbol{e}}+\boldsymbol{d} \cos \boldsymbol{\beta}}\right)^{1 / \boldsymbol{e}}\left(\frac{\boldsymbol{d}_{\boldsymbol{e}}+\boldsymbol{d} \cos \boldsymbol{\beta}}{\boldsymbol{d}_{\boldsymbol{e}}-\boldsymbol{d} \cos \boldsymbol{\beta}}\right)\left(\frac{1}{\boldsymbol{k}}\right)^{\frac{1}{\boldsymbol{e}}} \\
& =\left(\frac{\boldsymbol{S}_{\max _{i}}}{\boldsymbol{S}_{\max _{\boldsymbol{o}}}}\right)^{n}\left(\frac{\boldsymbol{d}_{\boldsymbol{e}}+\boldsymbol{d} \cos \boldsymbol{\beta}}{\boldsymbol{d}_{\boldsymbol{e}}-\boldsymbol{d} \cos \boldsymbol{\beta}}\right)^{(1-1 / \boldsymbol{e})}\left(\frac{1}{\boldsymbol{k}}\right)^{\frac{1}{e}}
\end{aligned}
$$

For ball bearings with $\boldsymbol{e}=1.11$ from Lundberg-Palmgren theory,

$$
\left(\frac{d_{e}-d \cos \beta}{d_{e}+d \cos \beta}\right)^{(1-1 / e)} \approx 1
$$

Accordingly, Eq. (15b) can be rewritten as

$$
X=\frac{L_{o}}{L_{i}} \approx\left(\frac{S_{\max _{i}}}{S_{\max _{o}}}\right)^{n}\left(\frac{1}{k}\right)^{\frac{1}{e}}
$$


In order to determine representative values of the correction factor $\boldsymbol{k}$ for stressed volume, the life ratios of the inner to outer races were calculated for three deep-groove bearing bore sizes, each having a zero internal diametrical clearance (IDC) using a computer code [15] that incorporates classical Lundberg-Palmgren theory to calculate bearing life. These results were compared to the ratio of inner- to outer-race lives calculated based on the ratio of the maximum Hertz stresses of the inner to outer races to the 9 th power. The conformities on the inner and outer races were 52 percent (0.52), the values used by the standards. The maximum Hertz stresses ranged from 1.47 to $2.33 \mathrm{GPa}$ (211 to $334 \mathrm{ksi}$ ). Using Eq. (16), the value of $\boldsymbol{k}$ for each of the three deep-groove ball bearing bore sizes was calculated. These results are shown in Table 1.

The differences in these life ratios calculated using the ratios of the Hertz stresses to the 9th power varied from 12 to 19 percent lower from those values calculated using the Lundberg-Palmgren theory. This difference can result in calculated fatigue lives as much as 10 percent higher than those calculated using the LundbergPalmgren theory for radially loaded deep-groove ball bearings. The calculated values of $\boldsymbol{k}$ varied from 0.80 to 0.87 (Table 1) for the arbitrarily selected bearing size example. For the purpose of simplicity, the $\boldsymbol{k}$ factor was assumed to be equal to one $(\boldsymbol{k}=1)$ for both angular-contact and deep-groove ball bearings. Accordingly, Eq. (16) becomes

$$
X=\frac{L_{o}}{L_{i}} \approx\left(\frac{S_{\max _{i}}}{S_{\max _{o}}}\right)^{n}
$$

Substituting Eqs. (4a) and (4b) into Eq. (17),

$$
\boldsymbol{X}=\frac{\boldsymbol{L}_{o}}{\boldsymbol{L}_{i}} \approx\left[\frac{\left(\frac{2 \cos \beta}{\boldsymbol{d}_{\boldsymbol{e}}-\boldsymbol{d} \cos \beta}+\frac{4}{\boldsymbol{d}}-\frac{1}{\boldsymbol{f}_{i} \boldsymbol{d}}\right)^{2 / 3}(\mu v)_{o}}{\left(-\frac{2 \cos \beta}{\boldsymbol{d}_{\boldsymbol{e}}+\boldsymbol{d} \cos \beta}+\frac{4}{d}-\frac{1}{f_{o} d}\right)^{2 / 3}(\mu v)_{i}}\right]^{n}
$$


Values of $\mu \nu$ for representative ball bearing series can be obtained from Table 2. Assuming $\cos \beta=1$ and $\boldsymbol{f}_{\boldsymbol{i}}=$ $\boldsymbol{f}_{\boldsymbol{o}}=0.52$, values of $\boldsymbol{L}_{\boldsymbol{o}} / \boldsymbol{L}_{\boldsymbol{i}}$ were calculated from Eq. (18) for $\boldsymbol{n}=9$ and 12 and are summarized in Table 3. It should be noted that in the development of these relationships it was assumed that the contact angle $\beta$ does not change with speed and load.

\section{Bearing Life Factors}

\section{Effect of Race Conformity}

The conformities at the inner and outer races affect the resultant Hertz stresses and the lives of their respective raceways. The determination of life factors $\boldsymbol{L} \boldsymbol{F}_{\boldsymbol{i}}$ and $\boldsymbol{L} \boldsymbol{F}_{\boldsymbol{o}}$ based on the conformities at the inner and outer races, respectively, can be calculated by normalizing the equations for Hertz stress for the inner and outer races to a conformity of 0.52 (the value of 0.52 was chosen as a typical reference value). Stresses are evaluated for the same race diameter as a function of conformity. Based on Eq. (9), the ratio of the stress at a 0.52 conformity to the value at the same normal load $\boldsymbol{P}_{\boldsymbol{N}}$ at each ball-race conformity, where $\boldsymbol{n}=9$ or 12, gives the appropriate life factor

$$
\boldsymbol{L F}=\left(\frac{\boldsymbol{S}_{\max _{0.52}}}{\boldsymbol{S}_{\max }}\right)^{\boldsymbol{n}}
$$

For the inner race,

$$
L F_{i}=\left[\frac{\left(\frac{2}{d_{e}-d}+\frac{4}{d}-\frac{1}{0.52 d}\right)^{2 / 3}(\mu v)_{i}}{\left(\frac{2}{d_{e}-d}+\frac{4}{d}-\frac{1}{f_{i} d}\right)^{2 / 3}(\mu v)_{0.52}}\right]^{n}
$$

and for the outer race, 


$$
\boldsymbol{L F}_{\boldsymbol{o}}=\left[\frac{\left(-\frac{2}{\boldsymbol{d}_{\boldsymbol{e}}+\boldsymbol{d}}+\frac{4}{\boldsymbol{d}}-\frac{1}{0.52 \boldsymbol{d}}\right)^{2 / 3}(\mu \mathrm{v})_{\boldsymbol{o}}}{\left(-\frac{2}{\boldsymbol{d}_{\boldsymbol{e}}+\boldsymbol{d}}+\frac{4}{\boldsymbol{d}}-\frac{1}{\boldsymbol{f}_{\boldsymbol{o}} \boldsymbol{d}}\right)^{2 / 3}(\mu \mathrm{v})_{0.52}}\right]^{n}
$$

The values of $(\mu v)_{0.52}$ are different for the inner and outer races.

For various ball bearing series, values of these life factors for conformities ranging from 0.505 to 0.570 , subject to round off error, are given for inner and outer races in Table 2 for $\boldsymbol{n}=9$ and 12 .

\section{Strict-Series System Reliability}

Lundberg and Palmgren [1] first derived the relationship between individual component life and system life. A bearing is a system of multiple components, each with a different life. As a result, the life of the system is different from the life of an individual component in the system. The fatigue lives of each of the bearing components are combined to calculate the system $\boldsymbol{L}_{\mathbf{1 0}}$ life using strict-series system reliability [1] and the twoparameter Weibull distribution function $\{11-13]$ for the bearing components comprising the system. Lundberg and Palmgren [1] expressed the bearing system fatigue life as follows:

$$
\frac{1}{\boldsymbol{L}_{10}^{\boldsymbol{e}}}=\frac{1}{\boldsymbol{L}_{10_{\boldsymbol{i}}}^{\boldsymbol{e}}}+\frac{1}{\boldsymbol{L}_{10_{\boldsymbol{o}}}^{\boldsymbol{e}}}
$$

where the life of the rolling elements, by inference, is incorporated into the life of each raceway tacitly assuming that all components have the same Weibull slope $\boldsymbol{e}$. In properly designed and operated rolling-element bearings, fatigue of the cage or separator in theory should not occur and, therefore, is not considered here in determining bearing life and reliability.

Where $\boldsymbol{X}=\boldsymbol{L}_{\boldsymbol{o}} / \boldsymbol{L}_{\boldsymbol{i}}$, Eq. (20a) can be rewritten as follows: 


$$
\boldsymbol{L}_{10}=\left(\frac{\boldsymbol{X}^{\boldsymbol{e}} \boldsymbol{L}_{\boldsymbol{i}}^{\boldsymbol{e}}}{\boldsymbol{X}^{\boldsymbol{e}}+1}\right)^{1 / \boldsymbol{e}}
$$

Applying life factors based on the effect of conformity on the respective lives of the inner- and outer-races, Eq. (20a) becomes

$$
L_{10_{m}}=\frac{\left(L F_{i}\right)\left(L F_{o}\right) X L_{i}}{\left[\left(L F_{o}\right)^{e} X^{e}+\left(L F_{i}\right)^{e}\right]^{1 / e}}
$$

Dividing Eq. (21) by (20b) provides the bearing life factor $\boldsymbol{L} \boldsymbol{F}_{\boldsymbol{c}}$ for ball bearing life based on Lundberg and Palmgren, recognizing combinations of race conformity but not considering ball life:

$$
\boldsymbol{L F}_{\boldsymbol{c}}=\left[\frac{\left(\boldsymbol{L} \boldsymbol{F}_{\boldsymbol{i}}\right)^{e}\left(\boldsymbol{L} \boldsymbol{F}_{\boldsymbol{o}}\right)^{e}\left(\boldsymbol{X}^{\boldsymbol{e}}+1\right)}{\left(\boldsymbol{L} \boldsymbol{F}_{\boldsymbol{o}}\right)^{\boldsymbol{e}} \boldsymbol{X}^{\boldsymbol{e}}+\left(\boldsymbol{L} \boldsymbol{F}_{\boldsymbol{i}}\right)^{\boldsymbol{e}}}\right]^{1 / \boldsymbol{e}}
$$

Referring to Eq. (7), the above life factor for conformity $\boldsymbol{L F}_{\boldsymbol{c}}$ is intended to be incorporated as an $\boldsymbol{a}_{3}$ life factor for "operating conditions." It does not include other factors associated with life factor $\boldsymbol{a}_{3}$, such as the lubricant film parameter orlife factor $\boldsymbol{a}_{2}$, such as material type and processing, or life factor.

\section{Zaretsky's Rule}

In order to precisely determine the combinations of race conformity, Hertz stress-life relation, and ball set life together with the lives of the inner and outer races, it is necessary to apply Zaretsky's rule [7]. To do so, Eq. (20a) should be written

$$
\left(\frac{1}{L_{10}}\right)^{e}=\left(\frac{1}{L_{i}}\right)^{e}+\left(\frac{1}{L_{r e}}\right)^{e}+\left(\frac{1}{L_{o}}\right)^{e}
$$

where the Weibull slope $\boldsymbol{e}$ is assumed to be the same for each of the components as well as for the bearing as a system. 
The $\boldsymbol{L}_{\mathbf{1 0}}$ life in Eq. (23) is the same as that for Eq. (20a). However, the $\boldsymbol{L}_{\boldsymbol{i}}$ and $\boldsymbol{L}_{\boldsymbol{o}}$ lives for Eq. (23) are not the same as those in Eq. (20a). In fact, they will be higher.

Deep-Groove Ball Bearings.-From Zaretsky's Rule for radially loaded ball bearings, the life of the rolling element set is equal to or greater than the life of the outer race. Let the life of the rolling element set as an entity be equal to that of the outer race. From Eq. (23), where $\boldsymbol{L}_{\boldsymbol{r} e}=\boldsymbol{L}_{\boldsymbol{o}}$

$$
\left(\frac{1}{L_{10}}\right)^{e}=\left(\frac{1}{L_{i}}\right)^{e}+2\left(\frac{1}{L_{o}}\right)^{e}
$$

With $\boldsymbol{X}=\boldsymbol{L}_{\boldsymbol{o}} / \boldsymbol{L}_{i}$, Eq. (24) can be rewritten as follows:

$$
\boldsymbol{L}_{10}=\left(\frac{\boldsymbol{X}^{\boldsymbol{e}} \boldsymbol{L}_{\boldsymbol{i}}^{\boldsymbol{e}}}{\boldsymbol{X}^{\boldsymbol{e}}+2}\right)^{1 / \boldsymbol{e}}
$$

Applying life factors based on the effect of conformity to the respective lives of the inner and outer races, Eq. (25) becomes

$$
L_{10_{m}}=\frac{\left(L F_{i}\right)\left(L F_{o}\right) X L_{i}}{\left[\left(L F_{o}\right)^{e} X^{e}+2\left(L F_{i}\right)^{e}\right]^{1 / e}}
$$

Dividing Eq. (26) by (25) provides the bearing life factor $\boldsymbol{L F}_{\boldsymbol{c}}$ for the radially-loaded deep-groove ball bearing based on conformity:

$$
\boldsymbol{L} \boldsymbol{F}_{\boldsymbol{c}}=\left[\frac{\left(\boldsymbol{L} \boldsymbol{F}_{\boldsymbol{i}}\right)^{\boldsymbol{e}}\left(\boldsymbol{L} \boldsymbol{F}_{\boldsymbol{o}}\right)^{\boldsymbol{e}}(\boldsymbol{X}+2)}{\left(\boldsymbol{L} \boldsymbol{F}_{\boldsymbol{o}}\right)^{\boldsymbol{e}} \boldsymbol{X}^{\boldsymbol{e}}+2\left(\boldsymbol{L} \boldsymbol{F}_{\boldsymbol{i}}\right)^{\boldsymbol{e}}}\right]^{1 / \boldsymbol{e}}
$$


Angular-Contact Ball Bearings._From Zaretsky's Rule for thrust-loaded ball bearings, the life of the rolling element set is equal to or greater than the life of the inner race but less than that of the outer race. Let the life of the rolling-element set as an entity be equal to that of the inner race. From Eq. (23), with $\boldsymbol{L}_{\boldsymbol{r e}}=\boldsymbol{L}_{\boldsymbol{i}}$

$$
\left(\frac{1}{L_{10}}\right)^{e}=2\left(\frac{1}{L_{i}}\right)^{e}+\left(\frac{1}{L_{o}}\right)^{e}
$$

With $\boldsymbol{X}=\boldsymbol{L}_{\boldsymbol{o}} / \boldsymbol{L}_{\mathrm{i}}$, Eq. (28) can be written as follows:

$$
\boldsymbol{L}_{\mathbf{1 0}}=\left(\frac{\boldsymbol{X}^{\boldsymbol{e}} \boldsymbol{L}_{\boldsymbol{i}}^{\boldsymbol{e}}}{2 \boldsymbol{X}^{\boldsymbol{e}}+1}\right)^{1 / e}
$$

Applying life factors based on the effect of conformity on the respective lives of the inner- and outer-races, Eq. (29) becomes

$$
L_{10_{m}}=\frac{\left(L F_{i}\right)\left(L F_{o}\right) X L_{i}}{\left[2\left(L F_{o}\right)^{e} X^{e}+\left(L F_{i}\right)^{e}\right]^{1 / e}}
$$

Dividing Eq. (30) by Eq. (29) provides the bearing life factor $\boldsymbol{L F}_{\mathbf{c}}$ for the thrust loaded, angular-contact ball bearing recognizing conformity:

$$
\boldsymbol{L} \boldsymbol{F}_{\boldsymbol{c}}=\left[\frac{\left(\boldsymbol{L} \boldsymbol{F}_{\boldsymbol{i}}\right)^{e}\left(\boldsymbol{L} \boldsymbol{F}_{\boldsymbol{o}}\right)^{e}\left(2 \boldsymbol{X}^{\boldsymbol{e}}+1\right)}{2\left(\boldsymbol{L} \boldsymbol{F}_{\boldsymbol{o}}\right)^{e} \boldsymbol{X}^{e}+\left(\boldsymbol{L} \boldsymbol{F}_{\boldsymbol{i}}\right)^{\boldsymbol{e}}}\right]^{1 / \boldsymbol{e}}
$$

Representative life factors $\boldsymbol{L F}_{\boldsymbol{c}}$ from Eqs. (22), (27), and (31) were determined based on four combinations of inner- and outer-race conformities and for three representative series, with the Lundberg-Palmgren theory and Zaretsky's rule. These results are summarized in Table 4, for the two Hertz stress-life exponents $\boldsymbol{n}=9$ and 12 . 


\section{Results and Discussion}

The effect of race conformity on ball life independent of race life is not by itself incorporated into the Lundberg-Palmgren fatigue life theory. In a previous analysis [8], Zaretsky, Poplawski, and Root considered the life of the ball set independently from race life, resulting in different life relations for deep-groove and angularcontact ball bearings. The Lundberg-Palmgren equations incorporate an inverse 9th power relation between Hertz stress and life. However, post-1960 vacuum-processed bearing steels exhibit a 12th power relation between Hertz stress and life. The work reported herein extends the above cited work to include this 12 th power relation.

Using Eqs. (22), (27), and (31), representative life factors $\boldsymbol{L} \boldsymbol{F}_{\boldsymbol{c}}$ were determined for extremely light, light, and heavy series deep-groove and angular-contact ball bearings for Hertz stress-life exponents $\boldsymbol{n}=9$ and 12 . The Lundberg-Palmgren theory does not qualitatively distinguish between a deep-groove and angular-contact ball bearing. That is, while the resultant lives may be different, the effect of the operating variables on the calculated bearing life is the same. In addition, ball life is not directly factored into the equations. Hence, while the initial Lundberg-Palmgren equations were benchmarked in the standards $[2,3]$ to inner- and outer-race conformities of 52 percent $(0.52)$, variation from this conformity can result in significant life variations.

As an example, for a light-series ball bearing where from Table $2 \boldsymbol{n}=9$, the outer-race conformity is 0.52 $\left(\boldsymbol{L} \boldsymbol{F}_{\boldsymbol{o}}=1\right)$, and the inner-race conformity is $0.505\left(\boldsymbol{L} \boldsymbol{F}_{\boldsymbol{i}}=12.32\right)$, and where from Table $3 \boldsymbol{X}=6.61$, the LundbergPalmgren prediction from Eq. (22) for the life factor $\boldsymbol{L} \boldsymbol{F}_{\boldsymbol{c}}$ is 5.10. When the inner-race conformity is changed to $0.57\left(L F_{i}=.10\right)$, the life factor $\boldsymbol{L} \boldsymbol{F}_{c}$ reduces to 0.11 , a 97.8 percent reduction.

Using Zaretsky's Rule, considering the effect of ball set life on the bearing fatigue life, the life factor $\boldsymbol{L F}_{\boldsymbol{c}}$ from Eqs. (27) and (31) at the 0.505 conformity decreases from 5.10 to 3.05 for deep-groove ball bearings and becomes 6.97 for angular-contact ball bearings. This is a life decrease of 40 percent for the deep-groove ball bearings and a life increase of 37 percent for the angular-contact ball bearing. For the same equivalent load $\boldsymbol{P}_{\boldsymbol{e q}}$ 
and dynamic capacity $\boldsymbol{C}_{\boldsymbol{D}}$, this calculation suggests that the angular-contact ball bearing should yield over twice the life of the deep-groove ball bearing.

At the 0.57 inner-race conformity, there is little difference between the Lundberg-Palmgren-based calculation of $\boldsymbol{L F}_{\boldsymbol{c}}=0.11$ and calculations using Lundberg-Palmgren theory with Zaretsky's Rule ( $\boldsymbol{L F}_{\boldsymbol{c}}$ values from Eq. (27) for deep-groove bearings and from Eq. (31) for angular-contact bearings are 0.10 and 0.11 , respectively).

While the calculations suggest that significant decreases in life for the deep-groove ball bearing due to considering conformity may be expected, in practice such decreases and/or differences have generally not been experienced or reported. The probable reasons for this are (1) that most rolling-element bearings are removed from service before they reach their calculated $\boldsymbol{L}_{\mathbf{1 0}}$ life, and (2) actual bearing lives are significantly longer than those calculated. Based on the data reported by Parker and Zaretsky [9] for vacuum-processed post-1960 bearing steels, the value of the load-life exponent $\boldsymbol{p}$ for ball bearings is 4 (not 3) and the Hertz stress-life exponent $\boldsymbol{n}=12$ (not 9); that is, $\boldsymbol{L}_{\mathbf{1 0}}=\left(\boldsymbol{C}_{\boldsymbol{D}} / \boldsymbol{P}_{\boldsymbol{e q}}\right)^{4}$ and not $\left(\boldsymbol{C}_{\boldsymbol{D}} / \boldsymbol{P}_{\boldsymbol{e q}}\right)^{3}$. Accordingly, the standards underpredict ball bearing life by a factor of $\left(\boldsymbol{C}_{\boldsymbol{D}} / \boldsymbol{P}_{e q}\right)$.

Referring to Table 4, where $\boldsymbol{n}=12(\boldsymbol{p}=4)$, in addition to the effect of conformity there is now the additional life factor of $\left(\boldsymbol{C}_{\boldsymbol{D}} / \boldsymbol{P}_{e q}\right)$. The significance of this factor is dependent on the actual load that is applied to the bearing. If the load $\boldsymbol{P}_{\boldsymbol{e q}}$ is $0.05 \boldsymbol{C}_{\boldsymbol{D}}$, this life factor is 20 times the reduction and/or increase in life because of conformity. Hence, for the light-series deep-groove bearing of Table 4, when $\boldsymbol{n}=12$ and where the outer-race conformity is 0.52 and the inner-race conformity is 0.505 , from Lundberg-Palmgren theory the life factor $\boldsymbol{L F}_{\boldsymbol{c}}$ is $9.67 \times 20=$ 193.4 without incorporating Zaretsky's rule. This is a significant increase in the life calculated from the ANSI/ABMA standards, where $\boldsymbol{L}_{10}=\left(\boldsymbol{C}_{\boldsymbol{D}} / \boldsymbol{P}_{\boldsymbol{e q}}\right)^{3}$ and the inner- and outer-race conformities are 0.52 .

Continuing to refer to Table 4 , for $\boldsymbol{n}=12$ and $\boldsymbol{p}=4$, with the inner-race conformity changed to 0.57 , the life factor $\boldsymbol{L} \boldsymbol{F}_{\boldsymbol{c}}$ reduces to $0.05 \times 20=1.00$. The inner-race conformity for this example produces the same life as the ANSI/ABMA standards calculation for inner- and outer-race conformities of 0.52 . For this example, the effect of 
race conformity would not be expected to be observed in an actual application when using the ANSI/ABMA standards to calculate fatigue life.

For inner-and outer-race conformities of 0.52 from the previous example, if instead of $\boldsymbol{P}_{\boldsymbol{e q}}=0.05 \boldsymbol{C}_{\boldsymbol{D}}$, a heavily loaded bearing is assumed where $\boldsymbol{P}_{\boldsymbol{e q}}=0.20 \boldsymbol{C}_{\boldsymbol{D}}$, the resultant life factor is 5 for a Hertz stress-life exponent of $\boldsymbol{n}=$ 12. From Table 4 for the light-series ball bearing and $\boldsymbol{n}=12$ where the outer-race conformity is 0.52 and the inner-race conformity is 0.505 , the bearing life factor $\boldsymbol{L} \boldsymbol{F}_{c}$ is $9.67 \times 5=48.35$. Where the inner-race conformity remains at 0.52 and the outer-race conformity is changed to 0.57 , the life factor $\boldsymbol{L} \boldsymbol{F}_{\boldsymbol{c}}$ reduces to $0.05 \times 5=0.25(\boldsymbol{n}$ $=12$ ). This value is over twice that calculated using Lundberg-Palmgren theory for $\boldsymbol{n}=9$, an inner-race conformity of 0.57 , and an outer-race conformity of 0.52 where $\boldsymbol{L F}_{\boldsymbol{c}}=0.11$.

Examination of Table 2 reveals that the relative life of individual races is more sensitive to changes in race conformities for $\boldsymbol{n}=12$ than for $\boldsymbol{n}=9$. However, when the effects are combined to predict actual bearing life for a specified set of conditions and bearing geometry, the predicted life of the bearing will be greater for a value of $\boldsymbol{n}$ $=12$ than for $\boldsymbol{n}=9$. Hence, for post-1960 vacuum-processed bearing steels it can be reasonably concluded that the unmodified Lundberg-Palmgren theory underpredicts bearing life where $\boldsymbol{L}_{10}=\left(\boldsymbol{C}_{\boldsymbol{D}} / \boldsymbol{P}_{\boldsymbol{e q}}\right)^{3}$. Accordingly, the bearing life in an actual application will be greater than that calculated using the ANSI/ABMA and ISO standards that incorporate the Lundberg-Palmgren theory.

Rolling-element bearing computer models are capable of handling various race conformities in combination with Lundberg-Palmgren theory, but they universally do not include the influence of ball-set life on overall bearing life. Computer programs acknowledging the influence of ball-set life are typically used for more rigorous analysis of bearing systems but are not commonly used in the general bearing design community. The contents of this paper enable the design engineer to calculate changes in bearing lives that include the life of the ball set and address the issue of race conformity. The life factors computed are intended to be combined with those that reflect influence of lubrication, materials, steel processing, and other environmental conditions from Ref. [7], pertinent to a particular application (Eq. (7)). 


\section{Summary of Results}

ANSI/ABMA and ISO standards based on Lundberg-Palmgren bearing life theory are normalized for ball bearings having inner- and outer-race conformities of 52 percent (0.52) and made from pre-1940 bearing steel. The Lundberg-Palmgren theory incorporates an inverse 9th power relation between Hertz stress and fatigue life for ball bearings. Except for differences in applied loading, deep-groove and angular-contact ball bearings are treated identically. The effect of race conformity on ball set life independent of race life is not incorporated into the Lundberg-Palmgren theory. In a previous analysis, Zaretsky, Poplawski, and Root considered the life of the ball set independently from race life, resulting in different life relations for deep-groove and angular-contact ball bearings. Post-1960 vacuum-processed bearing steel exhibits a 12th power relation between Hertz stress and life. The work reported herein extends the previous analysis to include this 12 th power relation. Equations are presented to calculate bearing life factors $(\boldsymbol{L F})$ to modify bearing life calculations based on these new relations. The contents of this paper enable the design engineer to calculate changes in bearing lives that includes the life of the ball set due to race conformity, Hertz stress-life exponent $\boldsymbol{n}$, ball bearing type and bearing series. The life factors computed are intended to be combined with those reflective of lubrication, materials processing, and other environmental conditions pertinent to a particular application. The following results were obtained:

1. For post-1960 bearing steels, the unmodified Lundberg-Palmgren theory where $\boldsymbol{L}_{10}=\left(\boldsymbol{C}_{\boldsymbol{D}} / \boldsymbol{P}_{\text {eq }}\right)^{3}$ underpredicts bearing fatigue life. The bearing life in actual application will usually be equal to or greater than that calculated using the ANSI/ABMA and ISO standards that incorporate the Lundberg-Palmgren theory.

2. The relative life of an individual race is more sensitive to changes in race conformity for Hertz stress-life exponent $\boldsymbol{n}=12$ than where $\boldsymbol{n}=9$. However, when the effects are combined to predict actual bearing fatigue life for a specified set of conditions and bearing geometry, the predicted life of the bearing will be greater for a value of $\boldsymbol{n}=12$ than for $\boldsymbol{n}=9$. 


\section{References}

[1] Lundberg, G., and Palmgren, A. (1947), "Dynamic Capacity of Rolling Bearings," Acta Polytechnica Mechanical Engineering Series, 1, 3, Stockholm, Sweden.

[2] ISO 298:1990(E) (1990), “Rolling Bearing-Dynamic Load Ratios and Rating Life,” International Organization for Standardization, Geneva.

[3] ANSI/ABMA 9-1990, "Load Ratings and Fatigue Life for Ball Bearings," The Anti-Friction Bearing Manufacturers Association, Washington, DC.

[4] ANSI/ABMA 11-1990, "Load Ratings and Fatigue Life for Roller Bearings," The Anti-Friction Bearing Manufacturers Association, Washington, DC.

[5] ANSI/ABMA 12.1-1985, "Instrument Ball Bearings Metric Design," The Anti-Friction Bearing Manufactures Association, Washington, DC.

[6] ANSI/ABMA 12.2-1985, "Instrument Ball Bearing Inch Design," The Anti-Friction Bearing Manufactures Association, Washington, DC.

[7] Zaretsky, E.V. (1992), STLE Life Factors for Rolling Bearings, STLE SP-34, Society of Tribologists and Lubrication Engineers, Park Ridge, IL.

[8] Zaretsky, E.V., Poplawski, J.V., and Root, L.E., (2007) "Reexamination of Ball-Race Conformity Effects on Ball Bearing Life,” Tribology Trans., 50, 3, pp. 336-349.

[9] Parker, R.J. and Zaretsky, E.V. (1972), "Reevaluation of the Stress-Life Relation in Rolling-Element Bearings," NASA TD-6745.

[10] Jones, A.B. (1946), Analysis of Stresses and Deflections, 1, 2, New Departure, Bristol, CT.

[11] Weibull, W. (1939), “A Statistical Theory of the Strength of Materials," Ingenioersvestenskapsakademiens. Handl., 151, Stockholm, Sweden.

[12] Weibull, W. (1939), “The Phenomenon of Rupture of Solids,” Ingeniorsvetenkapsakademiens. Handl., 153, Stockholm, Sweden. 
[13] Weibull, W. (1951), “A Statistical Distribution Function of Wide Applicability,” J. Appl. Mech. Trans. ASME, 18, 3, pp. 293-297.

[14] Zaretsky, E. V., Poplawski, J. V., and Peters, S. M., (1996), “Comparison of Life Theories for RollingElement Bearings,” Tribology Trans, 39, 1, pp. 237 - 248.

[15] Poplawski, J.V.; Rumbarger, J.H.; Peters, S.M.; Flower, R.; and Gelatis, H. (2002): “Advanced Analysis Package for High Speed Multi-Bearing Shaft Systems (COBRA-AHS); Final Report,” NASA Contract NAS3-00018. 
TABLE 1.-COMPARISON OF OUTER- TO INNER-RACE LIFE RATIOS, $\boldsymbol{L}_{\boldsymbol{i}} / \boldsymbol{L}_{\boldsymbol{o}}$, BASED ON

LUNDBERG-PALMGREN (L-P) THEORY AND RATIO OF INNER- TO OUTER-RACE

MAXIMUM HERTZ STRESS TO $9^{\text {th }}$ POWER FOR THREE

DEEP-GROOVE BALL BEARING SIZES.

[Bearing internal diametrical clearance, 0; maximum Hertz stresses, 1.47 to $2.33 \mathrm{GPa}$ (211 to $344 \mathrm{ksi}$ )]

\begin{tabular}{|c|c|c|c|c|c|}
\hline $\begin{array}{c}\text { Bearing bore } \\
\text { size, } \\
\mathrm{mm}\end{array}$ & $\begin{array}{c}\text { Ratio of inner- } \\
\text { to outer-race } \\
\text { maximum Hertz } \\
\text { stress, } \\
\left(\boldsymbol{S}_{\mathbf{m a x}_{\boldsymbol{i}}} / \boldsymbol{S}_{\mathbf{m a x}_{\boldsymbol{o}}}\right)\end{array}$ & $\begin{array}{c}\text { Ratio of outer to inner race lives, } \\
\boldsymbol{L}_{\boldsymbol{i}} / \boldsymbol{L}_{\boldsymbol{o}}\end{array}$ & $\begin{array}{c}\text { Difference between L-P } \\
\text { theory and Hertz stress } \\
\text { ratio, } \\
\text { theory }\end{array}$ & $\begin{array}{c}\text { From Hertz stress } \\
\text { ratio to } 9^{\text {th }} \text { power }\end{array}$ & $\begin{array}{c}\text { Stressed volume } \\
\text { correction factor, } \\
\boldsymbol{k}\end{array}$ \\
\hline 60 & 1.134 & 3.54 & 3.11 & & \\
\hline 100 & 1.166 & 4.84 & 3.98 & -12.1 & 0.87 \\
\hline 160 & 1.155 & 4.50 & 3.66 & -17.8 & .80 \\
\hline
\end{tabular}


TABLE 2.-EFFECT OF RACE CONFORMITY AND HERTZ STRESS-LIFE EXPONENT $\boldsymbol{n}$ ON BALL BEARING LIFE AS FUNCTION OF BALL BEARING SERIES*

\begin{tabular}{|c|c|c|c|c|c|c|}
\hline \multirow{6}{*}{$\begin{array}{c}\text { Conformity, } \\
\boldsymbol{f}\end{array}$} & \multicolumn{6}{|c|}{ Ball bearing series } \\
\hline & \multirow{2}{*}{\multicolumn{6}{|c|}{ Extremely light, $\frac{\boldsymbol{d} \cos \boldsymbol{\beta}}{\boldsymbol{d}_{\boldsymbol{e}}}=0.15$}} \\
\hline & & & & & & \\
\hline & \multicolumn{3}{|c|}{ Inner race } & \multicolumn{3}{|c|}{ Outer race } \\
\hline & \multirow[t]{2}{*}{$(\mu v)_{i}$} & \multicolumn{2}{|c|}{ Life factor, $\boldsymbol{L} \boldsymbol{F}_{\boldsymbol{i}}$} & \multirow[t]{2}{*}{$\overline{(\mu v)_{o}}$} & \multicolumn{2}{|c|}{ Life factor, $\boldsymbol{L} \boldsymbol{F}_{\boldsymbol{o}}$} \\
\hline & & $n=9$ & $n=12$ & & $n=9$ & $n=12$ \\
\hline 0.505 & 2.013 & 14.7 & 36.05 & 1.826 & 11.84 & 27.00 \\
\hline .510 & 1.776 & 4.53 & 7.51 & 1.673 & 3.61 & 5.53 \\
\hline .515 & 1.641 & 2.12 & 2.73 & 1.551 & 1.71 & 2.05 \\
\hline .520 & 1.517 & 1.00 & 1.00 & 1.471 & 1.00 & 1.00 \\
\hline .525 & 1.503 & 0.88 & 0.84 & 1.415 & 0.66 & 0.57 \\
\hline .530 & 1.452 & .62 & .53 & 1.369 & .46 & .36 \\
\hline .535 & 1.409 & .45 & .35 & 1.335 & .35 & .25 \\
\hline .540 & 1.376 & .35 & .25 & 1.304 & .27 & .17 \\
\hline .545 & 1.361 & .30 & .20 & 1.282 & .22 & .13 \\
\hline .550 & 1.328 & .23 & .14 & 1.262 & .18 & .10 \\
\hline .555 & 1.306 & .19 & .11 & 1.244 & .15 & .08 \\
\hline .560 & 1.296 & .17 & .10 & 1.227 & .13 & .06 \\
\hline .565 & 1.278 & .15 & .08 & 1.211 & .11 & .05 \\
\hline \multirow[t]{2}{*}{.570} & 1.262 & .13 & .06 & 1.196 & .09 & .04 \\
\hline & \multicolumn{6}{|c|}{ Extra light, $\frac{\boldsymbol{d} \cos \boldsymbol{\beta}}{\boldsymbol{d}_{\boldsymbol{e}}}=0.18$} \\
\hline 0.505 & 2.048 & 12.58 & 29.27 & 1.887 & 11.88 & 27.10 \\
\hline .510 & 1.784 & 3.47 & 5.25 & 1.662 & 3.54 & 5.40 \\
\hline .515 & 1.654 & 1.68 & 1.99 & 1.541 & 1.68 & 2.00 \\
\hline .520 & 1.570 & 1.00 & 1.00 & 1.465 & 1.00 & 1.00 \\
\hline .525 & 1.505 & 0.66 & 0.57 & 1.407 & 0.65 & 0.57 \\
\hline .530 & 1.458 & .47 & .37 & 1.364 & .47 & .36 \\
\hline .535 & 1.441 & .41 & .30 & 1.345 & .39 & .28 \\
\hline .540 & 1.398 & .30 & .20 & 1.303 & .28 & .18 \\
\hline .545 & 1.366 & .23 & .14 & 1.276 & .22 & .13 \\
\hline .550 & 1.336 & .18 & .10 & 1.254 & .17 & .10 \\
\hline .555 & 1.307 & .15 & .08 & 1.234 & .14 & .08 \\
\hline .560 & 1.301 & .13 & .07 & 1.212 & .12 & .06 \\
\hline .565 & 1.283 & .11 & .06 & 1.204 & .10 & .05 \\
\hline \multirow[t]{2}{*}{.570} & 1.267 & .10 & .05 & 1.192 & .09 & .04 \\
\hline & \multicolumn{6}{|c|}{ Light, $\frac{\boldsymbol{d} \cos \beta}{\boldsymbol{d}_{\boldsymbol{e}}}=0.23$} \\
\hline 0.505 & 2.062 & 12.32 & 28.38 & 1.870 & 11.83 & 26.94 \\
\hline .510 & 1.843 & 4.28 & 6.95 & 1.652 & 3.61 & 5.54 \\
\hline .515 & 1.658 & 1.58 & 1.84 & 1.549 & 1.89 & 2.34 \\
\hline .520 & 1.583 & 1.00 & 1.00 & 1.454 & 1.00 & 1.00 \\
\hline .525 & 1.520 & 0.67 & 0.58 & 1.397 & 0.66 & 0.57 \\
\hline .530 & 1.471 & .48 & .37 & 1.354 & .47 & .36 \\
\hline .535 & 1.431 & .36 & .25 & 1.333 & .38 & .28 \\
\hline .540 & 1.401 & .28 & .19 & 1.292 & .27 & .18 \\
\hline .545 & 1.374 & .22 & .14 & 1.267 & .21 & .13 \\
\hline .550 & 1.347 & .19 & .11 & 1.235 & .16 & .09 \\
\hline .555 & 1.324 & .15 & .08 & 1.227 & .14 & .08 \\
\hline .560 & 1.312 & .14 & .07 & 1.211 & .12 & .06 \\
\hline .565 & 1.298 & .12 & .06 & 1.198 & .10 & .05 \\
\hline .570 & 1.280 & .10 & .05 & 1.180 & .09 & .04 \\
\hline
\end{tabular}

\begin{tabular}{|c|c|c|c|c|c|c|}
\hline \multirow{5}{*}{$\begin{array}{c}\text { Conformity, } \\
f\end{array}$} & \multicolumn{6}{|c|}{ Ball bearing series } \\
\hline & \multicolumn{6}{|c|}{ Medium, $\frac{\boldsymbol{d} \cos \boldsymbol{\beta}}{\boldsymbol{d}_{\boldsymbol{e}}}=0.25$} \\
\hline & \multicolumn{3}{|c|}{ Inner race } & \multicolumn{3}{|c|}{ Outer race } \\
\hline & \multirow[t]{2}{*}{$(\mu v)_{i}$} & \multicolumn{2}{|c|}{ Life factor, $\boldsymbol{L} \boldsymbol{F}_{\boldsymbol{i}}$} & \multirow[t]{2}{*}{$(\mu v)_{\mathrm{o}}$} & \multicolumn{2}{|c|}{ Life factor, $\boldsymbol{L} \boldsymbol{F}_{\boldsymbol{o}}$} \\
\hline & & $n=9$ & $n=12$ & & $n=9$ & $n=12$ \\
\hline 0.505 & 2.067 & 11.78 & 26.82 & 1.878 & 12.34 & 28.53 \\
\hline .510 & 1.893 & 5.11 & 8.81 & 1.623 & 3.09 & 4.50 \\
\hline .515 & 1.684 & 1.71 & 2.04 & 1.524 & 1.64 & 1.93 \\
\hline .520 & 1.594 & 1.00 & 1.00 & 1.454 & 1.00 & 1.00 \\
\hline .525 & 1.548 & 0.74 & 0.67 & 1.393 & 0.64 & 0.55 \\
\hline .530 & 1.483 & .48 & .38 & 1.350 & .45 & .35 \\
\hline .535 & 1.442 & .36 & .26 & 1.314 & .33 & .23 \\
\hline .540 & 1.409 & .28 & .19 & 1.285 & .26 & .16 \\
\hline .545 & 1.382 & .23 & .14 & 1.253 & .19 & .11 \\
\hline .550 & 1.360 & .19 & .11 & 1.234 & .16 & .09 \\
\hline .555 & 1.338 & .16 & .09 & 1.214 & .13 & .07 \\
\hline .560 & 1.318 & .14 & .07 & 1.206 & .12 & .06 \\
\hline .565 & 1.304 & .12 & .06 & 1.186 & .09 & .04 \\
\hline \multirow[t]{2}{*}{.570} & 1.289 & .10 & .05 & 1.190 & .09 & .04 \\
\hline & \multicolumn{6}{|c|}{$\frac{\boldsymbol{d} \cos \boldsymbol{\beta}}{\boldsymbol{d}_{\boldsymbol{e}}}=0.28$} \\
\hline 0.505 & 2.056 & 11.87 & 27.08 & 1.874 & 13.02 & 30.62 \\
\hline .510 & 1.784 & 3.18 & 4.17 & 1.637 & 3.58 & 5.47 \\
\hline .515 & 1.668 & 1.62 & 1.97 & 1.519 & 1.70 & 2.03 \\
\hline .520 & 1.583 & 1.00 & 1.00 & 1.443 & 1.00 & 1.00 \\
\hline .525 & 1.547 & 0.78 & 0.72 & 1.387 & 0.66 & 0.57 \\
\hline .530 & 1.472 & .48 & .38 & 1.345 & .47 & .36 \\
\hline .535 & 1.435 & .37 & .27 & 1.310 & .34 & .24 \\
\hline .540 & 1.400 & .29 & .19 & 1.282 & .27 & .17 \\
\hline .545 & 1.373 & .23 & .14 & 1.260 & .22 & .13 \\
\hline .550 & 1.346 & .19 & .11 & 1.231 & .17 & .09 \\
\hline .555 & 1.327 & .16 & .09 & 1.217 & .14 & .07 \\
\hline .560 & 1.310 & .14 & .07 & 1.206 & .12 & .06 \\
\hline .565 & 1.292 & .12 & .06 & 1.191 & .10 & .05 \\
\hline .570 & 1.283 & .11 & .05 & 1.180 & .09 & .04 \\
\hline
\end{tabular}

*All values of $\boldsymbol{L} \boldsymbol{F}_{\boldsymbol{i}}$ and $\boldsymbol{L} \boldsymbol{F}_{\boldsymbol{o}}$ are normalized to 1.00 for conformity $f$ of 0.520 . 
TABLE 3.-REPRESENTATIVE RATIOS OF OUTER- TO INNER-RACE LIFE, $\boldsymbol{L}_{\boldsymbol{o}} / \boldsymbol{L}_{\boldsymbol{i}}$ FOR REPRESENTATIVE BALL BEARING SERIES AS A FUNCTION OF HERTZ STRESS-LIFE EXPONENT, $\boldsymbol{n}$, AT INNER- AND OUTERRACE CONFORMITIES OF 0.52 [From Eq. (17).]

\begin{tabular}{|c|c|c|c|}
\hline \multirow[t]{3}{*}{ Ball bearing series } & \multirow[t]{3}{*}{$\frac{d \cos \boldsymbol{\beta}}{d_{e}}$} & \multicolumn{2}{|c|}{$\begin{array}{c}\text { Outer- to inner-race } \\
\text { life ratio, } \\
\boldsymbol{X}=\boldsymbol{L}_{\boldsymbol{o}} / \boldsymbol{L}_{\boldsymbol{i}}\end{array}$} \\
\hline & & \multicolumn{2}{|c|}{$\begin{array}{c}\text { Hertz stress-life } \\
\text { exponent, } \\
\boldsymbol{n}\end{array}$} \\
\hline & & 9 & 12 \\
\hline Extremely light & 0.15 & 4.35 & 7.11 \\
\hline Extra light & .18 & 4.39 & 7.18 \\
\hline Light & .23 & 6.61 & 12.40 \\
\hline Medium & .25 & 8.36 & 16.96 \\
\hline Heavy & .28 & 12.04 & 27.60 \\
\hline
\end{tabular}


TABLE 4.--LIFE FACTORS BASED ON COMBINATIONS OF BALL-RACE CONFORMITIES FOR HERTZ STRESSLIFE EXPONENT $\boldsymbol{n}=9$ AND 12 NORMALIZED TO INNER- AND OUTER-RACE CONFORMITIES OF 0.52

\begin{tabular}{|c|c|c|c|c|c|c|c|}
\hline \multirow{3}{*}{$\begin{array}{c}\text { Ball bearing } \\
\text { series }\end{array}$} & \multirow{2}{*}{\multicolumn{2}{|c|}{ Ball-race conformity }} & \multicolumn{5}{|c|}{ Bearing life factor for conformity, ${ }^{1} \boldsymbol{L} \boldsymbol{F}_{c}$} \\
\hline & & & \multirow{2}{*}{\begin{tabular}{|l|} 
Lundberg- \\
Palmgren \\
from Eq. (22)
\end{tabular}} & \multicolumn{2}{|c|}{ Deep-groove ball bearing } & \multicolumn{2}{|c|}{ Angular-contact ball bearing } \\
\hline & $\begin{array}{l}\text { Inner-race, } \\
\text { IR }\end{array}$ & $\begin{array}{c}\text { Outer-race, } \\
\text { OR }\end{array}$ & & $\begin{array}{c}\text { From } \\
\text { Eq. (27) }\end{array}$ & $\begin{array}{l}\text { Change from } \\
\text { Lundberg- } \\
\text { Palmgren, } \\
\text { percent }\end{array}$ & $\begin{array}{c}\text { From } \\
\text { Eq. }(31)\end{array}$ & $\begin{array}{l}\text { Change from } \\
\text { Lundberg- } \\
\text { Palmgren, } \\
\text { percent }\end{array}$ \\
\hline \multicolumn{8}{|c|}{ Hertz stress-life exponent $\boldsymbol{n}=9$ and $\boldsymbol{L}_{\mathbf{1 0}}=$} \\
\hline \multirow{4}{*}{$\begin{array}{l}\text { Extremely light, } \\
\frac{d \cos \beta}{d_{e}}=0.15\end{array}$} & 0.505 & 0.52 & 4.16 & 3.15 & -24.30 & 7.40 & -77.83 \\
\hline & .57 & .52 & 0.15 & 0.15 & 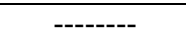 & 0.14 & -6.59 \\
\hline & .52 & .505 & 1.16 & 1.19 & 0.03 & 1.09 & -6.23 \\
\hline & .52 & .57 & 0.35 & 0.22 & -37.11 & 0.45 & 29.83 \\
\hline \multirow{4}{*}{$\begin{array}{l}\text { Light, } \\
\frac{d \cos \beta}{d_{e}}=0.23\end{array}$} & .505 & .52 & 5.10 & 3.05 & -40.28 & 6.97 & 36.76 \\
\hline & .57 & .52 & 0.11 & 0.10 & -9.09 & 0.11 & ------- \\
\hline & .52 & .505 & 1.10 & 1.04 & -5.68 & 7.05 & -4.42 \\
\hline & .52 & .57 & 0.49 & 0.27 & -39.04 & 0.59 & 35.15 \\
\hline \multirow{4}{*}{$\begin{array}{l}\text { Heavy, } \\
\frac{d \cos \beta}{d_{e}}=0.28\end{array}$} & .505 & .52 & 6.77 & 4.66 & -32.24 & 8.51 & 25.73 \\
\hline & .57 & .52 & 0.12 & 0.10 & -18.53 & 0.09 & -26.03 \\
\hline & .52 & .505 & 1.05 & 0.89 & -15.08 & 1.03 & -2.22 \\
\hline & .52 & .57 & 0.59 & 0.31 & $\begin{array}{l}-46.87 \\
\end{array}$ & 0.73 & 24.15 \\
\hline \multicolumn{8}{|c|}{ Hertz stress-life exponent $\boldsymbol{n}=12$ and $\boldsymbol{L}_{\mathbf{1 0}}=\left(\frac{\boldsymbol{C}_{\boldsymbol{D}}}{\boldsymbol{P}_{\mathbf{e q}}}\right)^{4}$} \\
\hline \multirow{4}{*}{$\begin{array}{l}\text { Extremely light, } \\
\frac{\boldsymbol{d} \cos \beta}{\boldsymbol{d}_{\boldsymbol{e}}}=0.15\end{array}$} & 0.505 & 0.52 & $6.83\left(\frac{C_{D}}{P_{\mathrm{eq}}}\right)$ & $3.65\left(\frac{C_{D}}{P_{\mathrm{eq}}}\right)$ & -46.56 & $10.79\left(\frac{C_{D}}{P_{\mathbf{e q}}}\right)$ & 57.98 \\
\hline & .57 & .52 & $0.07\left(\frac{C_{D}}{P_{\mathrm{eq}}}\right)$ & $0.06\left(\frac{C_{D}}{P_{\mathrm{eq}}}\right)$ & -14.29 & $0.06\left(\frac{C_{D}}{P_{\mathrm{eq}}}\right)$ & -14.29 \\
\hline & .52 & .505 & $1.10\left(\frac{C_{D}}{P_{\mathrm{eq}}}\right)$ & $1.02\left(\frac{C_{D}}{P_{\mathrm{eq}}}\right)$ & -7.27 & $1.05\left(\frac{C_{D}}{P_{\mathrm{eq}}}\right)$ & -4.55 \\
\hline & .52 & .57 & $0.26\left(\frac{C_{D}}{P_{\mathrm{eq}}}\right)$ & $0.14\left(\frac{C_{D}}{P_{\mathrm{eq}}}\right)$ & -46.15 & $0.39\left(\frac{C_{D}}{P_{\mathbf{e q}}}\right)$ & 50.00 \\
\hline \multirow{4}{*}{$\begin{array}{l}\text { Light, } \\
\frac{d \cos \beta}{d_{e}}=0.23\end{array}$} & .505 & .52 & $9.67\left(\frac{C_{D}}{P_{\mathrm{eq}}}\right)$ & $5.03\left(\frac{C_{D}}{P_{\mathrm{eq}}}\right.$ & -47.98 & $14.03\left(\frac{C_{D}}{P_{\mathrm{eq}}}\right)$ & 45.09 \\
\hline & .57 & .52 & $0.05\left(\frac{C_{D}}{P_{\mathrm{eq}}}\right)$ & $0.04\left(\frac{C_{D}}{P_{\text {eq }}}\right)$ & -20.00 & $0.05\left(\frac{C_{D}}{P_{\mathrm{eq}}}\right)$ & ------- \\
\hline & .52 & .505 & $1.05\left(\frac{C_{D}}{P_{\mathrm{eq}}}\right)$ & $0.89\left(\frac{\boldsymbol{C}_{\boldsymbol{D}}}{\boldsymbol{P}_{\mathbf{e q}}}\right)$ & -15.24 & $1.03\left(\frac{C_{D}}{P_{\mathrm{eq}}}\right)$ & -1.90 \\
\hline & .52 & .57 & $0.37\left(\frac{\boldsymbol{C}_{\boldsymbol{D}}}{\boldsymbol{P}_{\mathrm{eq}}}\right)$ & $0.20\left(\frac{\boldsymbol{C}_{\boldsymbol{D}}}{\boldsymbol{P}_{\mathbf{e q}}}\right)$ & -45.95 & $0.53\left(\frac{C_{D}}{P_{\mathbf{e q}}}\right)$ & 43.24 \\
\hline \multirow{4}{*}{$\begin{array}{l}\text { Heavy, } \\
\frac{\boldsymbol{d} \cos \boldsymbol{\beta}}{\boldsymbol{d}_{\boldsymbol{e}}}=0.28\end{array}$} & .505 & .52 & $14.97\left(\frac{C_{D}}{P_{\text {eq }}}\right)$ & $7.81\left(\frac{C_{D}}{P_{\mathbf{e q}}}\right)$ & -47.83 & $19.13\left(\frac{C_{D}}{P_{\mathrm{eq}}}\right)$ & 27.79 \\
\hline & .57 & .52 & $0.05\left(\frac{C_{D}}{P_{\text {eq }}}\right)$ & $0.04\left(\frac{C_{D}}{P_{\text {eq }}}\right)$ & -20.00 & $0.05\left(\frac{C_{D}}{P_{\mathbf{e q}}}\right)$ & -------- \\
\hline & .52 & .505 & $1.02\left(\frac{C_{D}}{P_{\mathrm{eq}}}\right)$ & $0.77\left(\frac{C_{D}}{P_{\mathbf{e q}}}\right)$ & -24.51 & $1.01\left(\frac{C_{D}}{P_{\mathbf{e q}}}\right)$ & -0.01 \\
\hline & .52 & .57 & $0.57\left(\frac{C_{D}}{P_{\text {eq }}}\right)$ & $0.30\left(\frac{\boldsymbol{C}_{\boldsymbol{D}}}{\boldsymbol{P}_{\mathrm{eq}}}\right)$ & -47.37 & $0.72\left(\frac{\boldsymbol{C}_{\boldsymbol{D}}}{\boldsymbol{P}_{\mathbf{e q}}}\right)$ & 26.32 \\
\hline
\end{tabular}

${ }^{1}$ All life factors are benchmarked to $\boldsymbol{L}_{10}=\left(\frac{\boldsymbol{C}_{\boldsymbol{D}}}{\boldsymbol{P}_{\mathbf{e q}}}\right)^{3}$ and inner- and outer-race conformities of 0.52 .

${ }^{2}$ For deep-groove and angular-contact ball bearings. 


\section{Figure Captions}

Figure 1.-Deep-groove ball bearing. (a) Schematic. (b) Cross section without cage.

Figure 2.-Ball-race conformity. (a) Deep-groove ball bearings. (b) Angular-contact ball bearing.

Figure 3.-Schematic of contact profile of ball on raceway. 


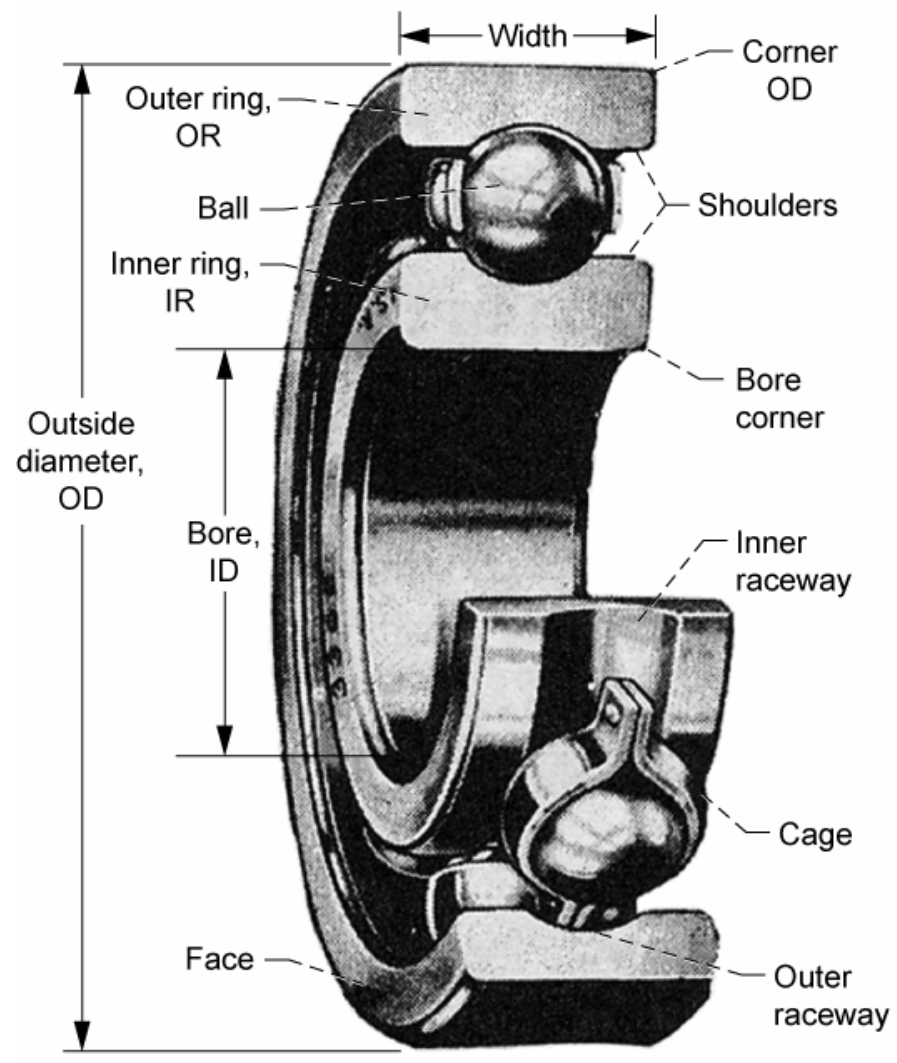

(a)

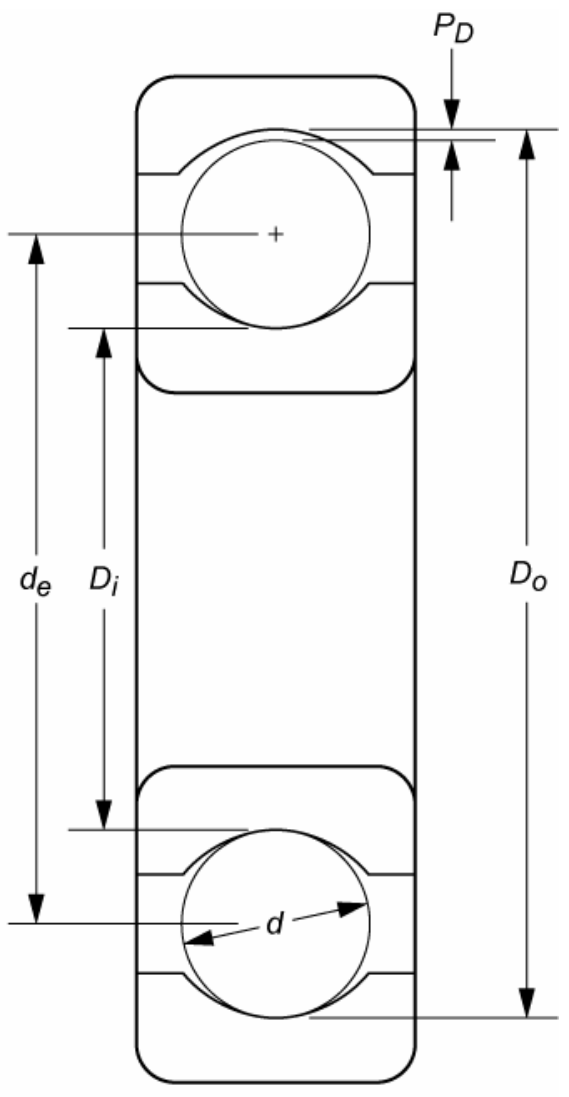

(b)

Figure 1.-Deep-groove ball bearing. (a) Schematic. (b) Cross section without cage. 
(a)

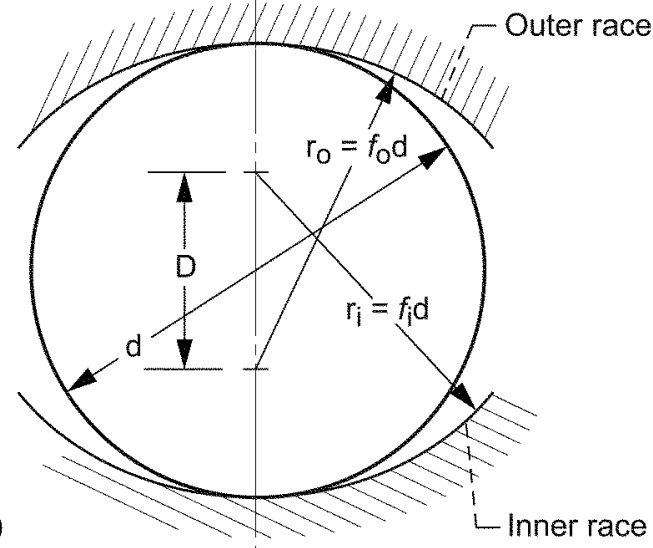

(b)

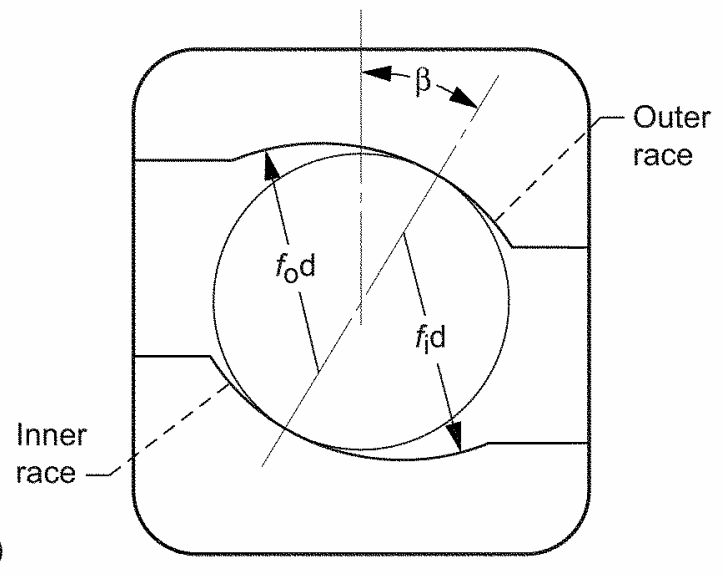

Figure 2.-Ball-race conformity. (a) Deep-groove ball bearing. (b) Angular-contact ball bearing. 


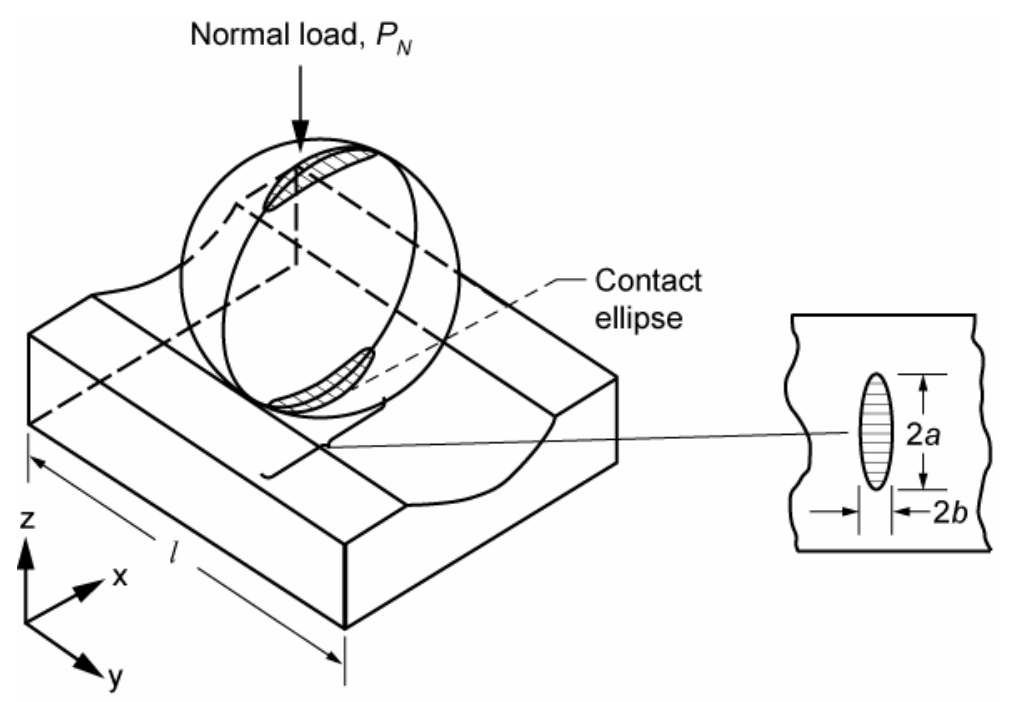

Figure 3.-Schematic of contact profile of ball on raceway. 